\title{
Support of Decision in Buildings Refurbishment with a Change of Utility
}

\author{
Aleksandra Radziejowska, Anna Sobotka, Joanna Sagan*
}

\begin{abstract}
Construction objects, including buildings, are characterized by a long period of use resulting from the properties of structural and material solutions properly designed constructed and operated. Practice shows that functional aging of buildings is faster than technical. Therefore, for these reasons and taking into account current socio-economic concepts (sustainable development, preservation of cultural heritage, economic, location reasons, etc.) buildings that have ceased to perform their current function are subject to renovation and / or refurbishment, enabling them to perform new functions compatible with social needs: public and commercial. The choice of new functions cannot be accidental. The decision-making process regarding the refurbishment of a building with a change of utility function is subject to high economic risk, which is why it should be carried out using a methodology that ensures a holistic approach. The paper proposes a methodology of functional and functional programming in the pre-investment phase of project preparation using multi-criteria analysis of the utility function selection. The methodology is illustrated by an example of the choice of function in the adaptation of a post-production building from public resources.
\end{abstract}

Keywords: change of utility; multi-criteria analysis; refurbishment

\section{INTRODUCTION}

In public resources of real estate objects are being the old historic building structures or buildings under conservation protection. They are both residential and postproduction buildings. From a technical point of view, they are in good technical condition or require repairs, but they no longer meet the original utility functions assumed at the time of their creation. Although they are, however, quite often in a state of degradation, their value as a cultural monument, historical or testimony of the then technique including construction, etc. is significant and worth preserving as an element of national heritage.

The choice of new utility functions in the programming process of an investment project, which is an adaptation of a building structure, usually combined with renovation and refurbishment works, is conditioned by many assumptions, restrictions - factors (technical, economic, social, environmental, etc.) and is a difficult interdisciplinary decision problem for the owner, investor and other participants in the project. In the case of public building resources, there is an opportunity when choosing to change the utility functions to consider those that provide increasing social needs whose satisfaction is statutorily supported by state administrative units (e.g. municipalities). The selection of new utility functions requires consideration of many factors and conditions, as well as many possibilities and presentation of variant solutions assessed using multi-criteria analysis [17-19].

The example presented in the article draws attention to two issues: functional aging of buildings from public resources (local government units or the State Treasury) and their adaptation to new functions ensuring the satisfaction of social needs, which is possible thanks to public co-financing. The utility function is selected in the pre-investment phase. The proposed methodology for defining the functional and utility modernization program promotes variant solutions and decisions supported by multi-criteria analysis.

\section{DECISION SUPPORT IN THE PROGRAMMING AND DESIGN PHASE OF BUILDING REFURBISHMENT}

Many important decisions are made in the planning process of building modernization with a change in utility function. Therefore, a holistic approach is needed, taking into account many aspects and requiring comprehensive knowledge related to the implementation of construction projects. In addition, it must be remembered that the economic efficiency of decisions taken at the building operation stage, in contrast to the preparatory phase of a new construction investment, is associated with high modernization costs. Managers and designers must face technical, economic and social challenges.

The project involving the modernization of the building with a change in the utility function requires carrying out all the actions that are required by applicable legal regulations regarding human activities in society in conducting business activities and related to the implementation of construction works [1]. Some projects require, apart from typical procedures (due to their specificity, e.g. historic buildings), additional activities.

Therefore, in the presented case study the following methodology was proposed:

I. Decision of modernization of the building, based on analysis of all conditions and restrictions, including technical condition, legal status (e.g. ownership, historic) regarding the selected object to be modernized. Initial technical research, query and analysis of archival materials.

II. Research related to the change of the utility function of the modernized facility: construction market research, surveying of social needs in the area of utility preferences, obtaining expert opinions.

III. Development of suggestions for building adaptation options for new functions.

IV. Ranking of solution variants based on multi-criteria analysis of the presented adaptation options, including 
life cycle costs and economic efficiency of the investment.

V. Defining the functional and utility program. Development of a feasibility study or business plan with SWOT (Strengths, Weaknesses, Opportunities, Threats) analysis to his final assessment.

VI. Decision to adapt the building to the selected utility function or withdraw from the decision.

The first four stages in the adopted methodology lead to the definition of a functional and utility variant program, and then its selection. While the selection is the basis for the preparation of technical documentation and implementation of subsequent stages of the project.

The presented scheme of conduct does not list exactly all stages and actions as well as making other important decisions in relation to the partial goals that make up the achievement of the goal of a given construction project. However, attention is paid primarily to making decisions based on the analysis of variant solutions of a given task (goal) and choosing the best one for given conditions (taking into account many necessary criteria), with an analysis of future scenarios of the effects of decisions made. In the investment process, the best efficiency is achieved by the right decisions in the pre-investment phase, and then project changes have the lowest costs at this stage.

It should be added that there are feedbacks between the mentioned stages of decision making, which require consideration of additional conditions and actions (e.g. extension of tests on the technical condition of the modernized building or reuse variants).

Public administration (state, local government units) are obliged to help and develop society, to meet social needs, including such as looking after children, the elderly, or providing cultural centers $[2,3]$. There are many needs and public funds are limited. Therefore, decisions regarding the choice of what needs and how to meet them, and what financial resources will be needed for the investment, is an extremely important decision.

Further in the paper, in the presented case study, research and their results will be presented, which are an example of the decision-making process of choosing a new utility function of a historic post-production building implemented from public resources.

\section{CASE STUDY}

\subsection{Description of the Building to be Adapted}

The development of an example multi-criteria analysis for the selection of a new utility function required the possession of the largest possible amount of real data, including the assessment of the technical condition of the building. Therefore, the process of choosing the utility function of the post-production building was illustrated based on the building of the former card factory, which was adapted for commercial purposes in 2019.

The analyzed building, built in 1921-1923 and used as a card factory, is located in the city center and is under conservation protection [4]. It is a six-storey, without a basement building, consisting of two dilated parts, of reinforced concrete frame structure with beam ceilings (Fig. 1 and 2).

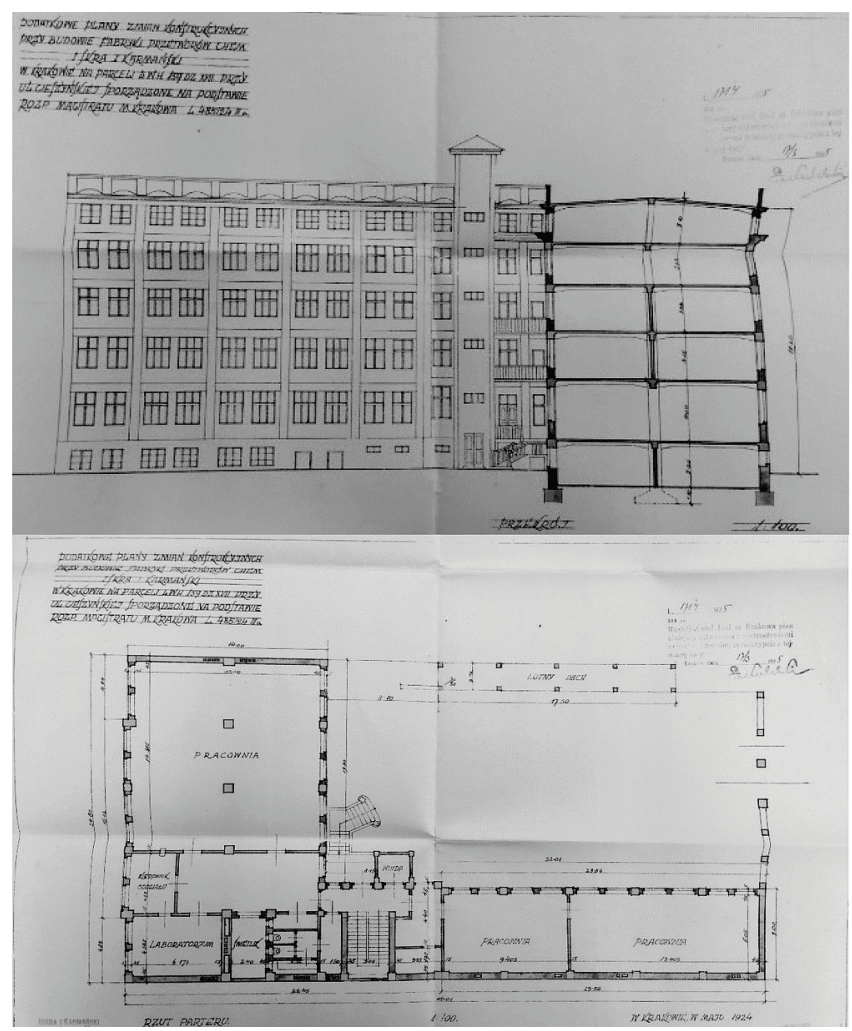

Figure 1 Sample technical drawings from the archival documentation of the factory building, Cracow, May 1924 [5]

The skeleton was filled with a brick wall $45 \mathrm{~cm}$ thick. The building was rebuilt several times. Figure 2 presented the appearance of the object before the renowation.

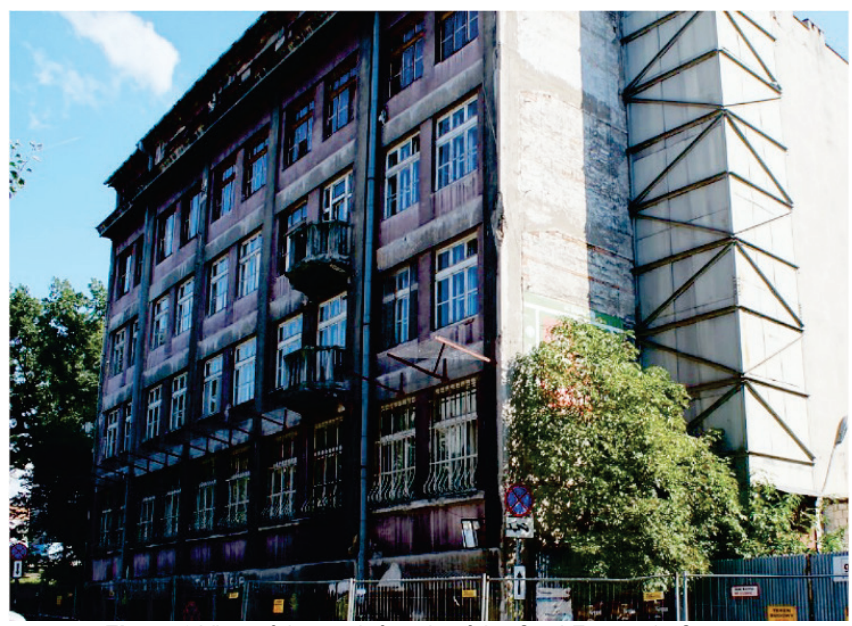

Figure 2 View of the north facade of the Card Factory in Cracow before the renovation [6]

In 2014, by decision of the Department of Culture and National Heritage, the building conditions were agreed, allowing the adaptation of the existing building for new development purposes. In June 2015, an expert opinion was made on the technical condition of the building structure, on 
the basis of which the necessary renovation works were established to restore the proper technical and aesthetic condition of the building and its safe use [7]. Permission was also given for the demolition of a part of the existing postindustrial building located deep inside the plot and the complete demolition of the remaining outbuilding. In sketch of the plot development of the modernized object and its designed dimensions as well as building visualization, made for the purpose of calculating the cost of adapting the building (Fig. 3).
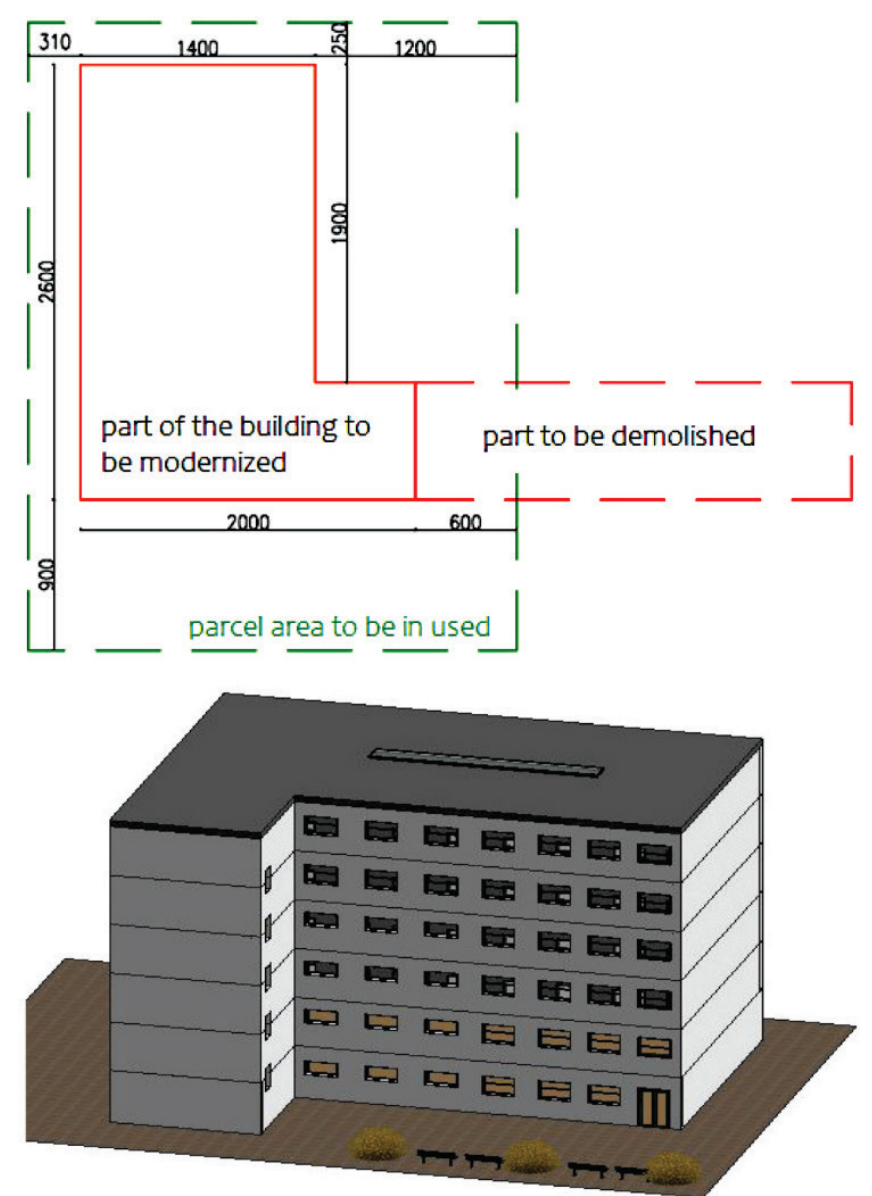

Figure 3 The modernized object and its designed dimensions as well as building visualization

\subsection{The Results of Research on the Change of Use of the Building}

Research on the selection of a new function of the analyzed building were included analysis of location and technical conditions (in terms of technical condition and technical possibilities of modernization and adaptation), expert opinions, and the opportunity to meet social needs and preferences. The latter mentioned aspect was examined on the basis of surveys using an online survey [8]. Factors that users value most during the operation of the facility were also identified. W The survey involved 100 respondents, including 90 people up to 30 years old, 7 respondents aged 31 to 50 years and 3 people over 51 years old. Interesting results of this research, characteristic of the majority of young respondents, are presented in Fig. 4. "Other" items include: library, garden and gallery, reading room, shopping and service building, community center, museum, school. The study participant had to choose up to three utility functions of the building from among those proposed in the survey. The most frequently indicated were: flats $(49 \%)$, gym $(34 \%)$, nursery/kindergarten (29\%), library $(25 \%)$ and offices $(24 \%)$.

What kind of new utility function would suit your needs?

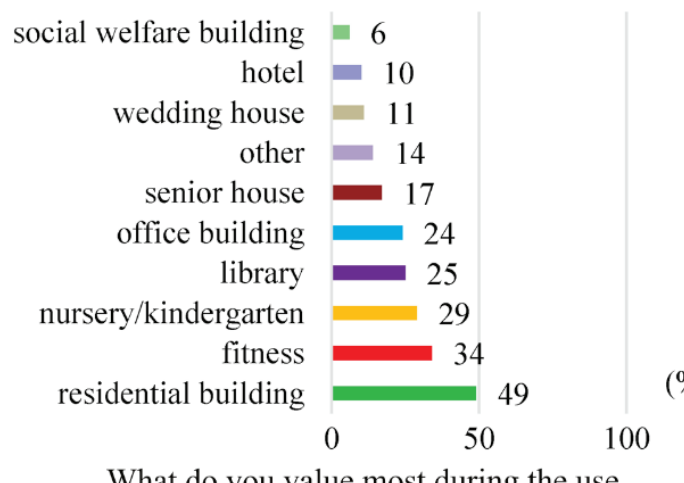

What do you value most during the use of the object?

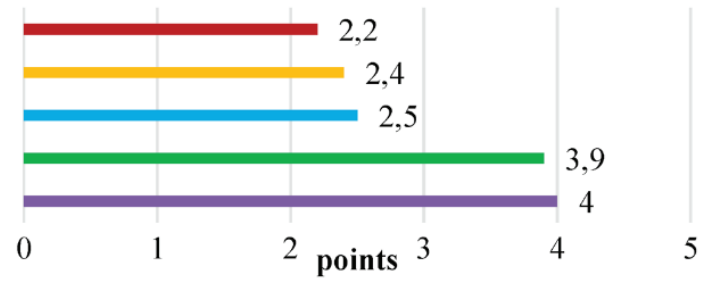

- K6 Functionality of the facilities

- K10 Comfort of use

- K2 Operating costs

K7 Modern technical solutions in the field of installation

- K11 Modern material solutions - building aesthetics Figure 4 Survey results [8]

In the opinion of other participants of the construction market, such as developers, investors, contractors of construction works, there is a high demand (in modernized buildings) for apartments, service and office premises, including rent. The demand also concerns nurseries and kindergartens, as well as nursing homes (retirement homes) for the elderly and, e.g. senior clubs, because of the aging of the population. In 2018, in Poland the percentage of $\in$ people aged 60 and over is $24.4 \%$ of the total population, including $8.3 \%$ people more than 85 years old [9].

Considering the results of the survey, it was decided to consider two variants of adaptation with multi-use functions. The first - kindergarten and nursery (max 120 children) on the lower floors and a library with a reading room on the upper floors, the ground floor will be designated as a service premises - a restaurant. The second variant: on the ground floor and first floor - a community center and a senior's house (max 62 people) on the other floors. 


\subsection{Technical Characteristics of Both Variants - Scope of Renovation and Modernization}

Given the technical condition of the building from the point of view of modernization, regardless of the type of future use, the building requires many renovation works, indicated in the technical expertise [7]. Those are:

- demolition of the slab between the ground floor and first floor and its re-construction, higher than the existing slab, due to the need to increase the usable height of the lower floor and which will allow obtaining the same heights on each floor. The height in the storey will be from $2.9-3.1 \mathrm{~m}$. The slab will be made in furrows in existing masonry walls, and on reinforced concrete elements joined with reinforced concrete columns.

- reconstruction of the communication shaft, including reconstruction of the staircase and incorporation of the elevator shaft,

- reinforcement of slabs,

- $\quad$ strengthening the foundations.

Other construction works included in the sample analysis are result from the adopted utility functions for two variants. Construction and material solutions in both variants are similar.

The estimated cost of adaptation for I variant is 682245 EUR, and in II - 1544512 EUR.

\subsection{Multi-Criteria Analysis of the Assessment of the Proposed Building Adaptation Solutions}

The proposed variants of changing the utility function of the analyzed building were subjected to multi-criteria analysis using two classic methods commonly known and described in the literature: synthetic indicators [10] (from the group of taxonomic methods $[20,21])$ and AHP (Analytical Hierarchy Process) [11, 22, 23, 24]. The set of proposed evaluation criteria is: $K_{1}$ - cost of renovation and modernization, $K_{2}$ - operating costs, $K_{3}$ - life cycle costs, $K_{4}$ - NPV (assessment of investment efficiency), $K_{5}$ - labor consumption, $K_{6}$ - surface division functionality, $K_{7}$ - modern technical solutions for installation, $K_{8}$ - nuisance of repairs for future users, $K_{9}$ - social need, $K_{10}$ - comfort of use, $K_{11-}$ modern material solution -building aesthetic.

Five out of eleven evaluation criteria were selected, based on the opinions of survey respondents, experts and those interested in the investment. Their mutual relations were taken into account in the selection of criteria. Weights of criteria in both methods of multi-criteria analysis were adopted according to the AHP method.

Particular attention was paid to the cost analysis. The $\left(K_{2}\right)$ criterion for the costs of building operating and the investment effectiveness determined by means of the NPVs (Net Present Value) [8] were taken into account, considering the period of 30 years of operation. In relation to the current approach to investment assessments, the total life cycle costs $\left(K_{3}\right)$, consisting of the costs of purchase, ownership and disposal of the building, were also determined [25]. The conducted cost assessment does not take into account the cost of disposal (demolition of building is not expected).

The cost calculation includes funding for kindergartens and nurseries, care for seniors, libraries and community centers by municipalities and required by law. The following assumptions were made in the calculations:

1. Subsidies for kindergartens [12] are calculated in accordance with Article 12 of the Act of 27 October 2017 on financing educational tasks [2]. In connection with the above, every year the commune receives a subsidy for pre-school education. In 2018, funding for the public kindergarten was 167 EUR / per child/ per month. For the purposes of calculating the cash flow for option I, the following were adopted:

The daily cost of maintaining a child in kindergarten is 4 EUR, assuming full board and additional hours for which the parent pays - the monthly cost is about 78 EUR. Co-financing from the commune for one child was founded 155 EUR per month.

2. Staying in the senior's home is paid and in accordance with art. 59 of the Act on social assistance [3], it is the commune body that decides about the costs of stay [13]. Act in art. 61 presents a list of persons who bear the costs of living a pensioner, showing who the payment obligation is transferred to. These are, in order: the inmate, spouse (s), descendants, ascending relatives, and commune.

A resident can pay a maximum of $70 \%$ of their income for their stay. The municipality, on the other hand, finances the difference between the average cost of living in a senior's home and the fees paid by the abovementioned persons [14]. For the purposes of article, the following was assumed: daily cost of staying in a senior's home - 20 EUR, including full board, medical care, rehabilitation, etc. - monthly -600 EUR. The income of the resident was assumed at the amount of 556 EUR and a monthly fee for his stay of 378 EUR, the remaining difference, i.e. $222 \mathrm{EUR}$, is paid by the commune.

Despite the income from the rental of service premises designed on the ground floor, NPV (Net Present Value) for both variants are less than zero (therefore investments are unprofitable, from the point of view of the investor, which is e.g. a commune). Annual cash flow is negative. Such NPV was predictable, however, this criterion was included in the assessment for comparative purposes, it is destimulant.

After selecting the criteria, determining their values and weights, global calculations of the proposed variants of the new form of use of the building began. Due to the subjective nature of multi-criteria analysis methods, two methods were used that did not require complicated calculations. The AHP method is well described in the literature and very popular [11]. The method of synthetic indicators consists in the construction of a scalar, whose numerical value is a synthetic assessment indicator. The study uses an additive corrected indicator $J$ according to the formula:

$J=\sum_{j=1}^{m}\left(z_{i j} \cdot w_{j}\right)$ 
where: $z_{i j}$ - a coded measure of the $i^{\text {th }}$ variant of the $j^{\text {th }}$ criterion, $w_{j}$ - weight of the $j^{\text {th }}$ criterion.

Coding, i.e. reducing the value of the criteria to an unnamed value, can be done using various methods. The article uses the standardization method [10,8]. Tab. 1 shows the final calculation results and all intermediate calculations are in the [8].

Table 1 Summary of the results of multi-criteria analysis, based on [8]

\begin{tabular}{|c|c|c|c|c|c|}
\hline \multirow{4}{*}{ 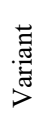 } & \multicolumn{5}{|c|}{ Criteria values } \\
\hline & $K_{2}$ & $K_{3}$ & $K_{4}$ & $K_{6}$ & $K_{9}$ \\
\hline & \multicolumn{5}{|c|}{ Weight $w(0 \div 1)$} \\
\hline & 0.31 & 0.42 & 0.06 & 0.04 & 0.17 \\
\hline$V_{1}$ & 374444 & 25939651 & -9156352 & 2 & 4 \\
\hline$V_{2}$ & 362667 & 25157343 & -8955058 & 4 & 5 \\
\hline \multicolumn{6}{|c|}{ Assessment result } \\
\hline & \multicolumn{2}{|c|}{ Synthetic indicators } & \multicolumn{3}{|c|}{ AHP - global priority } \\
\hline$V_{1}$ & \multicolumn{2}{|c|}{0.141} & \multicolumn{3}{|c|}{0.346} \\
\hline$V_{2}$ & \multicolumn{2}{|c|}{0.173} & \multicolumn{3}{|c|}{0.651} \\
\hline
\end{tabular}

$K_{2}$ - operating costs (EUR), $K_{3}$ - life cycle costs (EUR), $K_{4}$ - NPV (EUR), $K_{6}$ - surface division functionality (1-5 scale), $K_{9}$ - social need (1-5 scale)

The calculations show that under the adopted conditions and assumptions, variant 2 - connecting the community center with the senior's house received a higher rating in both the AHP method and the synthetic assessment method. The largest impact on the analysis result was the value of cofinancing allocated by the commune for the given units, because in the case of kindergarten they accounted for about $60 \%$ of the total operating costs of the facility, and in the option with the senior's home, the costs of co-financing constituted about $45.6 \%$ of the operating costs. Such a difference in the scale of the year is a considerable expense for local governments, which provide subsidies for the functioning of such facilities every year.

\section{SUMMARY}

The buildings are characterized by a long period of existence, in good technical condition, with their proper use and maintenance. They "age" faster in functional terms. The choice of a new function, building and its adaptation and modernization is a very complex and responsible decisionmaking process. Requires consideration of many aspects.

In the example of decision making process presented in the article, the multi-criteria analysis method was used.

Among the many methods presented in the literature (e.g. $[15,16]$ ), classical ones, which do not require special mathematical preparation, and with some practice - not consuming were chosen. The advantage of multi-criteria analysis is the inclusion of a holistic approach in solving problems and making decisions.

This approach is required in the pre-investment phase and the construction project preparation process. In the topic presented in the article on the selection of the utility function of buildings aging from public post-production resources, this approach is particularly recommended. The choice of function should take into account many aspects: technical, economic, social. In the case of investments financed from public funds and being part of the state's obligations in the field of social assistance, the economic efficiency factor mainly plays an informative role, although it may have a weight. Therefore, the final decision regarding the choice of adaptation of a given building should be made after the development of the functional and utility program and the feasibility study re-evaluated, e.g. using SWOT analysis. This is the last item in the proposed methodology for identifying the construction investment program.

Apart from the huge needs in terms of access to public kindergartens or senior homes, the building chosen for analysis was in fact adopted as an office building. This choice was also accurate due to its location in the city center, the needs of the real estate market and technical reasons. The structural and functional layout of the modernized building did not require significant changes, and therefore did not entail additional expenditure on its adaptation.

\section{Notice}

The paper will be presented at PBE2020 - International Scientific Conference "People, Buildings and Environment 2020 ". The $14^{\text {th }}$ conference will be held in the Rožnov pod Radhoštěm city, the Czech Republic, from 7 to 9 October 2020. The paper will not be published anywhere else.

\section{REFERENCES}

[1] Polish parliament (1994). Act of 7 July 1994. Construction law.

[2] Polish parliament (2017). Act of 27 October 2017 on financing educational tasks.

[3] Polish Parliament (2004). Act of 12 March 2004 on social assistance.

[4] Polish Parliament (2003). Act of 23 July 2003 on the protection care over monuments. Poland.

[5] Facility documentation. (1924). Archives of the City of Krakow at Lubicz 25 b street.

[6] Daraż, D. (2019). Office building "Factory of carts", street Cieszynska 13. https://investmap.pl/inwestycja/krakowbiurowiec-fabryka-kart-ul-cieszynska-13,9469.html

[7] GSBK Company. (2015). Expertise of the technical condition of the building structure of the Trefl Card Factory in Cracow.

[8] Zięba, K. (2019). Modernization of the selected building object with a change in the utility function. AGH University of Science and Technology.

[9] Joint publication chaired by Ewa Kamińska Gawryluk. (2020). The situation of older people in Poland in 2018. file://C:/Users/User/Downloads/sytuacja_osob_starszych_w_ polsce_w_2018.pdf

[10] Szwabowski, J. \& Deszcz, J. (2001). Multi-criteria analysis methods, theoretical basis and examples of applications in construction. Wydawnictwo Politechniki Śląskiej.

[11] Saaty, T. L. (1990). How to make a decision: The analytic hierarchy process. European Journal of Operational Research. https://doi.org/10.1016/0377-2217(90)90057-I

[12] Korfel-Jasińska, A. (2018). Subsidies for kindergartens in 2018 - EC announcement. https://www.krakow.pl/aktualnosci/ 216859,34,komunikat,dotacje_dla_przedszkoli_w_2018_r komunikat_wydzialu edukacji.html

[13] $\bar{K}$ lukowska, K. (2019). Social welfare building. Gazeta Wyborcza. wyborcza.pl

[14] Sierpowska, I. (2020). The state and social assistance. Department of Political Doctrine of the Faculty of Law, Administration and Economics of the Wroclaw University. 
[15] Zavadskas, E. K., Antuchevičien, J., \& Kapliński, O. (2015). Multi-criteria decision making in civil engineering: Part I--a state-of-the-art survey. Engineering Structures and Technologies, 7(3), 103-113. https://doi.org/10.3846/2029882X.2015.1143204

[16] Zavadskas, E. K., Vainiunas, P., Turskis, Z., \& Tamosaitiene, J. (2012). Multiple criteria decision support system for assessment of projects managers in construction. International Journal of Information Technology \& Decision Making, 11(02), 501-520. https://doi.org/10.1142/S0219622012400135

[17] Federica Ribera, F., Nesticò, A., Cucco, P., \& Maselli, G. (2020). A multicriteria approach to identify the Highest and Best Use for historical buildings. Journal of Cultural Heritage, 41, 166-177. https://doi.org/10.1016/j.culher.2019.06.004

[18] Radziszewska-Zielina, E. \& Sladowski, G. (2017). Supporting the selection of a variant of the adaptation of a historical building with the use of fazzy modelling and structural analysis. Journal of Cultural Heritage, 26, 53-63. https://doi.org/10.1016/j.culher.2017.02.008

[19] Tzeng, G-H. \& Huang, J-J. (2011) Multiple Attribute Decision Making: Methods and Applications CRC Press, Taylor \& Francis Group, USA. https://doi.org/10.1201/b11032

[20] Helwig, Z. (1968). The use of the taxonomic method for the typological division of countries by level of their development and the resources and structure of qualified staff, Statistical Review, No. 4 (in Polish).

[21] Pluta, W. Multidimensional comparative analysis in economic research. Taxonomic methods and factor analysis, Państwowe Wydawnictwo Ekonomiczne, Warsaw (in Polish).

[22] Korytárová, J., Hromádka, V., \& Dufek, Z. (2018). Use of multi-criteria analysis for selecting a desirable project solution variant of making an important waterway navigable in Radziszewska-Zielina, E., (ed.) Planning and organisation in modern construction - selected aspects, Press Politechnika Krakowska, Krakow, 121-144.

[23] Radziszewska-Zielina, E. (2016). The application of multicriteria analysis in the evaluation of partnering relations and the selection of a construction company for the purposes of cooperation. Archives of Civil Engineering, 62(02), 167-182. https://doi.org/10.1515/ace-2015-0072

[24] Marović, I. \& Hanak, T. (2017). Selection of adequate site location during early stages of construction project management: A multi-criteria decision analysis approach. IOP Conference Series: Materials Science and Engineering. https://doi.org/10.1088/175-7899X/251/1/012044

[25] Biolek, V. \& Hanák, T. (2019). LCC Estimation Model: A Construction Material Perspective. Buildings, 9(8), 182. https://doi.org/10.3390/buildings9080182

\section{Authors' contacts:}

Aleksandra Radziejowska, Dr. Eng.

AGH University of Science and Technology,

al. Mickiewicza 30, A1-301, 30-059 Krakow, Poland

+48126174771, aradziej@agh.edu.pl

Anna Sobotka, Professor

AGH University of Science and Technology,

al. Mickiewicza 30, A1 -123, 30-059 Krakow, Poland

+ 481261721 91, sobotka@agh.edu.pl

Joanna Sagan, Dr. Eng.

AGH University of Science and Technology

al. Mickiewicza 30, A1-301, 30-059 Krakow, Poland

+48 1261747 71, Joanna.sagan@agh.edu.pl 